\title{
Associations of symptoms of anxiety disorders and self-reported behavior problems in normal children
}

Citation for published version (APA):

Muris, P., Merckelbach, H., Moulaert, V., \& Gadet, B. (2000). Associations of symptoms of anxiety disorders and self-reported behavior problems in normal children. Psychological Reports, 86(1), 86-86. https://doi.org/10.2466/pr0.2000.86.1.157

Document status and date:

Published: 01/01/2000

DOI:

10.2466/pro.2000.86.1.157

Document Version:

Publisher's PDF, also known as Version of record

\section{Please check the document version of this publication:}

- A submitted manuscript is the version of the article upon submission and before peer-review. There can be important differences between the submitted version and the official published version of record.

People interested in the research are advised to contact the author for the final version of the publication, or visit the DOI to the publisher's website.

- The final author version and the galley proof are versions of the publication after peer review.

- The final published version features the final layout of the paper including the volume, issue and page numbers.

Link to publication

\footnotetext{
General rights rights.

- You may freely distribute the URL identifying the publication in the public portal. please follow below link for the End User Agreement:

www.umlib.nl/taverne-license

Take down policy

If you believe that this document breaches copyright please contact us at:

repository@maastrichtuniversity.nl

providing details and we will investigate your claim.
}

Copyright and moral rights for the publications made accessible in the public portal are retained by the authors and/or other copyright owners and it is a condition of accessing publications that users recognise and abide by the legal requirements associated with these

- Users may download and print one copy of any publication from the public portal for the purpose of private study or research.

- You may not further distribute the material or use it for any profit-making activity or commercial gain

If the publication is distributed under the terms of Article $25 \mathrm{fa}$ of the Dutch Copyright Act, indicated by the "Taverne" license above, 
Verdachten beweren nogal eens een alcohol-

black-out te hebben gehad tijdens het delict dat

hun ten laste wordt gelegd. Komt zo'n black-

out echt voor of is het een middel om straf-

rechtelijke verantwoordelijkheid te minimali-

seren? De frequen-

Wetenschap

\section{Acoholblacknouly woor een delict: bestarit dat}

Alcoholgebruik leidt geregeld tot agressief gedrag dat de allure van een misdrijf kan aannemen. Neem bijvoorbeeld het incident in mei 2002 waarbij een man na het drinken van drie tot vijf dubbele glazen whisky een hem onbekende jongen zonder aanleiding doodschoot voor café Cetto's in Den Haag. De verdachte zei later zich niets te kunnen herinneren van de schietpartij. Zijn laatste herinnering vóór het incident betrof een glas whisky en een stukje kip in een nabijgelegen café. Zijn eerste herinnering na het incident was het moment dat hij op het politiebureau uit zijn roes 'wakker' werd. Dat beweerde de verdachte tenminste.

Het komt wel vaker voor dat verdachten beweren tijdens een delict een black-out te hebben gehad vanwege ruime hoeveelheden geconsumeerde alcohol. Alcohol is inderdaad én van de psychoactieve drugs die kunnen leiden tot een blackout.' Black-outs treden vaak op bij zware drinkers en alcoholisten (Anthenelli et al., 1994; Goodwin, 1995). Vanwege de hoge prevalentie van alcoholblack-outs onder zware drinkers, werd in de oudere literatuur een black-out geïnterpreteerd als mogelijke indicator voor toekomstig alcoholisme Jellinek, 1946). Het meeste onderzoek naar black-outs in de afgelopen vijftig jaar richtte zich dan ook op alcoholisten. Uit verschillende studies blijkt echter dat niet alleen alcoholisten, maar ook gezonde studenten op ruime schaal black-outs rapporteerden (Anthenelli et al., 1994; Goodwin, 1995; White et al., 2002). In de studies van Anthenelli (1994) en Goodwin (1995) rapporteerde respectievelijk $25 \%$ en $33 \%$ van de gezonde respondenten wel eens een black-out te hebben gehad. Blijkbaar zijn black-outs niet per definitie een voorspeller van alcoholisme. Uit deze studies werd echter niet goed duidelijk voor welk soort gebeurtenissen mensen een black-out kunnen hebben. Dat ligt wat anders voor een e-mailonderzoek onder Amerikaanse studenten. Daarin rapporteerde $51 \%$ van de studenten wel eens een black-out te hebben gehad (White et al., 2002). In die studie ging het om black-outs voor risicovol tie en aard van

black-outrapporta-

ges in een gewone

steekproef werden

vergeleken met

Kim van Oorsoum, Harald Merckelbach, Dick Ravelli, Henk Nijman en Ingrid Mekking-Pompen

gedrag zoals onverantwoord seksueel contact en autorijden.

Ofschoon er dus wel onderzoek is gedaan naar het voorkomen van black-outs bij niet-specifieke groepen, richtten genoemde studies zich vooral op de relatie tussen black-outs en toekomstige alcoholproblematiek en minder op die tussen black-outs en deviant gedrag. Wij waren geïnteresseerd in die tweede relatie. Er zijn in dat verband twee belangrijke vragen te beantwoorden. Ten eerste rijst de vraag welk soort gebeurtenis ten prooi kan vallen aan black-outs. Is het wel zo vanzelfsprekend dat iemand zich later zijn agressief gedrag niet meer kan herimneren omdat hij of zij onder invloed van alcohol verkeerde? Ten tweede is het interessant om te weten hoeveel iemand moet hebben gedronken om een black-out te krijgen. Voor verdachten of daders kan immers straf- of schuldvermindering een motief zijn om een black-out te rapporteren (Good, 1989; Polster, 1993).

Om meer zicht te krijgen op deze kwesties, voerden we een exploratieve studie uit naar drinkgedrag en ervaringen met black-outs onder 256 respondenten (178 vrouwen). Deze gegevens werden verkregen op basis van retrospectieve rapportages. Uit de aard van de zaak kunnen daarbij allerlei vertekeningen optreden. In een tweede studie onderzochten we daarom de relatie tussen alcoholgebruik en black-out bij een groep van 101 automobilisten die waren aangehouden voor rijden onder invloed. Het voordeel van deze benadering is dat het alcoholpromillage - in het kader van art. 8 van de Verkeerswegenwet 1994 - met een bloedproef werd bepaald. Mogelijk geheugenverlies voor het delict werd later, in het kader van de beoordeling van de rijgeschiktheid, standaard uitgevraagd door een hiervoor door het Centraal Bureau voor Rijvaardigheidsbewijzen (CBR) aangezochte psychiater (D.R.). Hierdoor kon dus het feitelijk vastgestelde alcoholpromillage in verband worden gebracht met het al dan niet rapporteren van een black-out. 


\section{Alcoholblack-out en geheugen}

Een alcoholblack-out kan worden gedefinieerd als geheugenverlies (amnesie) voor een periode van alcoholintoxicatie. Gedurende die periode is er iets noemenswaardigs gebeurd waarvan de persoon achteraf kennis neemt en zodoende tot de conclusie komt dat hij of zij zich de betreffende gebeurtenis niet meer kan herinneren. Aldus gedefinieerd is een alcoholblack-out een vorm van retrograde amnesie (zie Kopelman, 1987, 1995): met terugwerkende kracht stelt de betrokkene vast dat hij zich iets niet meer kan herinneren. Een voorwaarde voor het optreden van een black-out is dat er een aanzienlijke hoeveelheid alcohol wordt geconsumeerd en de bloedalcoholconcentratie dusdanig hoog is dat er een 'dissociatieve' toestand optreedt. Het gaat dan om een verandering of verstoring van de normale geïntegreerde functies van bewustzijn, geheugen, identiteit of motorisch gedrag zonder dat er bewustzijnsdaling plaatsvindt (Good, 1989). Gedurende de black-out is de persoon wakker, bewust en maakt op zijn omgeving een nog redelijk georiënteerde indruk. Een blackout is niet per definitie onomkeerbaar. Het komt voor dat iemand zich later de gebeurtenissen weer kan herinneren, met behulp van cues dan wel spontaan (Good, 1989).

Het werkend bestanddeel van alcohol is ethanol. Deze st of ondermijnt de functie van hersencentra die betrokken zijn bij gedragsinhibitie (Critchlow, 1986). Ook dempt hij de activiteit van neuronen betrokken bij bewegingscoördinatie, bewustzijn en geheugen. Deze functies zullen dan ook bij overmatig alcoholgebruik aangetast raken. Gedragskenmerken zijn dat de persoon in kwestie trager gaat praten, niet meer zo stevig op de benen staat en een minder goed geheugen heeft voor zich op dat moment afspelende gebeurtenissen (Neal, Scott \& Grimsbo, 1993). Dit roept de vraag op of iemand die zodanig veel alcohol heeft gedronken dat zijn geheugen niet meer functioneert, fysiek wel in staat is de motorische handelingen uit te voeren die nodig zijn voor een delict. Kalant (1996; p. 638) meent van niet: 'De typische uitwerking van alcohol op het brein is het progressief, en min of meer parallel, doen afnemen van alle typen zenuwcelactiviteit, inclusief die betrokken bij gecoördineerde bewegingen en bij bewustzijn en geheugen.' Het is precies deze overweging die het onwaarschijnlijk maakt dat iemand een black-out ontwikkelt voor complex delictwaardig gedrag zoals dat bijvoorbeeld aan de orde was in de eerder aangehaalde Cettozaak.

Er zijn twee potentiële mechanismen die aan alcoholblack-outs ten grondslag Iiggen. Het eerste mechanisme benadrukt een defect in de registratie van informatie, het zogenaamde encoderen. Bij zeer hoge bloedalcoholconcentraties vindt er een tijdelijke ontregeling plaats van biochemische reacties in het brein die noodzakelijk zijn voor de aanleg van nieuwe geheugensporen (Kalant, 1996). Recente bevindingen tonen aan dat het om specifieke veranderingen in activiteit van de hippocampus gaat, een breinstructurur betrokken bij leren en geheugen (White, Matthews \& Best, 2000). Het tweede mechanisme benadrukt het fenomeen van toestandsafhankelijk (state-dependent) leren en zogenaamde ophaalpro- cessen (retrieval). Informatie die in geïntoxiceerde toestand in het geheugen wordt opgeslagen, zou in nuchtere toestand niet teruggevonden kunnen worden. Het feit dat sommige mensen beweren zich bepaalde gebeurtenissen wél weer te kunnen herinneren als ze opnieuw dronken zijn, zou deze theorie ondersteunen (Fillmore, Vogel-Sprott \& Gavrilescu, 1999; Goodwin, 1995; Goodwin, Crane \& Guze, 1969; Swihart, Yuille \& Porter, 1999). ${ }^{2}$

\section{Motivatie en verwachtingen}

Behalve biologische mechanismen kunnen ook psychologische factoren een verklaring bieden voor het verschijnsel van alcoholblack-out. Te denken valt dan aan attributie en verwachtingseffecten. Het kan goed van pas komen om ongepast gedrag te rechtvaardigen met een beroep op overmatig alcoholgebruik. In landen als Canada en de Verenigde Staten roept het vaak sterke associaties op met automatisch gedrag en 'loss of criminal intent'. Beide aspecten kunnen voor een verdachte gunstig uitpakken als het gaat om de schuldvraag (Crombag, 2002; Kalant, 1996). Illustratief in dit verband is de Canadese zaak Deviault $v$. R. waarbij een man terechtstond wegens aanranding. De man beweerde tot zijn daad te zijn gekomen onder invloed van alcohol. Hij zei ook dat hij zich zijn gedrag niet meer kon herinneren. De jury oordeelde dat de aanranding een vorm van 'automatisme' was geweest en sprak de man vrij, wat tot grote publieke verontwaardiging leidde. In Nederland zou een dergelijke vrijspraak ondenkbaar zijn vanwege de hier heersende 'culpa in causa'-doctrine. Volgens deze doctrine mag men ervan uitgaan dat een verdachte op de hoogte is van de gevolgen van overmatig alcoholgebruik. Daarnaast mag het dan wel zo zijn dat intoxicatie het geheugen ondermijnt, maar gedrags- of fatsoensregels opgeslagen in het langetermijngeheugen blijven toegankelijk. De verdachte is dus wel degelijk in staat om zich te realiseren dat wat hij wil gaan doen, fout is (Goodwin, 1995).

Verwachtingen van mensen over alcohol, hebben een grote invloed op de gedragseffecten ervan. Terwijl de "culpa in causa'-doctrine tot de standaardbagage van juristen behoort, zijn veel leken stilzwijgende aanhangers van de opvatting dat iemand die onder invloed verkeert, minder verantwoordelijk kan worden gehouden voor zijn daden (Critchlow, 1986). Op de vraag wat de positieve effecten van alcohol zijn, zal een groot aantal mensen antwoorden dat het je losser maakt en remmingen wegneemt. Ook de negatieve effecten, zoals agressief gedrag, worden geacht een effect van deze disinhibitie te zijn. Placebostudies laten zien dat ontremd gedrag niet per se een effect van alcohol hoeft te zijn, maar ook door verwachtingen kan worden bepaald. In deze studies vertonen mensen die ten onrechte denken alcohol te hebben gebruikt, ook kenmerken van gedragsdisinhibitie. Zulke placebo-effecten strekken zo ver dat ook het geheugen door verwachtingen wordt ondermijnd (Assefi \& Garry, 2003).

Op grond van deze overwegingen rijst de vraag in welke mate alcoholblack-outs buiten de rechtszaal voorkomen Anders gezegd: zijn black-outs een handig gelegenheidsar- 
gument dan wel een op verwachtingen gebaseerde attributie van verdachten die hun gedrag proberen te verontschuldigen? In dat laatste geval is het van belang om te weten of zulke black-outs ook gerapporteerd worden buiten de rechtszaal, dus door mensen uit de algemene populatie. Als dat zo is, wordt het interessant te weten wat mensen dan zeggen te hebben gedronken voorafgaand aan de black-out. Een laatste maar zeer belangrijke vraag is of de black-out zich richt op deviant gedrag. Om op deze kwesties meer zicht te krijgen, namen wij een vragenlijst af in een algemene steekproef.

\section{Black-outs}

Bij 256 personen tussen de 18 en 82 jaar oud werd een vragenlijst ${ }^{3}$ afgenomen waarin respondenten moesten aangeven hoe vaak en hoeveel alcohol ze gemiddeld dronken per maand en of ze wel eens een black-out hadden gehad ten gevolge van de consumptie van alcohol. Onder black-out werd verstaan: 'door het drinken van alcohol een stukje van de avond of dag niet meer kunnen herinneren'. Indien respondenten aangaven wel eens zo'n black-out te hebben gehad, werd hun naar details van de situatie gevraagd. Meer specifiek moesten respondenten vragen beantwoorden over hun fysieke gesteldheid, druggebruik en eetgedrag in de periode vlak voor de black-out. Tevens werden vragen gesteld over de hoeveelheid alcohol en het tijdsbestek waarin die geconsumeerd was, lichaamsgewicht en lengte. De bedoeling hiervan was een grove indicatie te krijgen van de bloedalcoholconcentraties (BAC) ten tijde van de black-out. Ook werd hun gevraagd wat de aard van de gebeurtenissen was die ten prooi vielen aan de black-out en hoelang de black-out duurde. Ten slotte werd de respondenten gevraagd of de herinneringen later weer waren teruggekomen. Als dat het geval was, werd gevraagd of dit 'geheugenherstel' spontaan was dan wel gestuurd door anderen.

Van de 256 respondenten dronken er 44 nooit alcohol. $\mathrm{Zij}$ werden uitgesloten van verdere analyses. De resterende groep van 212 drinkers bestond uit 138 vrouwen en 78 mannen, met een gemiddelde leeftijd van 25,0 jaren. In deze groep zei $67 \%$ (142 mensen, waarvan 84 vrouwen en 58 mannen met een gemiddelde leeftijd van 25,0 jaren) wel eens een black-out te hebben gehad. Gemiddeld beweerden de drinkende respondenten zo'n 2,4 keer $(S D=1,3)$ in hun leven een black-out te hebben ervaren. Eveneens gemiddeld zouden er voorafgaand aan deze black-outs binnen vier uur vijftien drankjes zijn geconsumeerd. Dat correspondeert met een gemiddelde bloedalcoholconcentratie $(\mathrm{BAC})$ van rond de 2,6 promille $(S D=$ $1,3){ }^{4,5}$ In $22 \%$ van de gevallen beweerden respondenten voorafgaand aan de black-out drugs te hebben gebruikt, niet te hebben gegeten en/of lichamelijk niet in orde te zijn geweest. Deze factoren kunnen hebben bijgedragen aan een toename van de bloedalcoholconcentraties en het ontstaan van blackouts. Maar in de meerderheid van de gerapporteerde gevallen (78\%) speelden deze factoren geen rol.

In de black-outgroep bleken mannen vaker $[t(140)=2,26$, $p<0,05]$ en meer $[t(126)=5,63, p<0,05]$ te drinken dan vrouwen. ${ }^{6}$ Mannen hadden tijdens gerapporteerde black-outs dan ook hogere BAC's dan vrouwen: $t(121)=2,93, p<0,005$ ? ${ }^{?}$ Het aantal black-outs dat werd gerapporteerd verschilde echter niet tussen mannen en vrouwen. Dit suggereert dat vrouwen gevoeliger zijn voor het optreden van black-outs. Zij dronken gemiddeld 4,0 keer per maand twaalf drankjes per keer waarbij ze BAC's van rond de 2,3 bereikten en rapporteerden dan even vaak black-outs als mannen, die gemiddeld 5,8 keer per maand 19 drankjes nuttigden en daarbij BAC's van 3,0 bereikten.

De duur van de black-out varieerde tussen de vijftien minuten en één uur. Gevraagd naar de aard van de gebeurtenissen waarvoor een black-out optrad, kwamen de volgende antwoorden het meest voor: 58\% van de respondenten gaf aan 'zich niet meer te kunnen herinneren met wie men had gesproken, $51 \%$ wist niet meer hoe men was thuisgekomen, $29 \%$ kon zich niet herinneren hoe men ergens was terechtgekomen, $25 \%$ kon zich niet meer herinneren te zijn gevallen, $23 \%$ kon zich niet meer herinneren zichzelf voor schut te hebben gezet en 20\% gaf aan zich te hebben misdragen. In $12 \%$ van de gevallen ging het om een ernstige gebeurtenis zoals een ruzie, vechtpartij of vernieling. Respondenten die rapporteerden een black-out te hebben gehad voor een ernstige gebeurtenis, bleken ongeveer vijf glazen meer te hebben gedronken dan de respondenten die een black-out hadden voor minder ernstige gebeurtenissen $t(126)=2,47, p<0,05$. Hun BAC's verschilden bijna 1,0 promille, wat bij eenzijdige toetsing significant bleek: $t(121)=2,28, p<0,05$. Hieruit zouden we kunnen afleiden dat als iemand ernstiger geïntoxiceerd is, de kans op afwijkend gedrag waarvoor later een black-out optreedt, toeneemt. Op de vraag of de herinneringen later terugkwamen, antwoordde $46 \%$ dat zij later spontaan terugkwamen. In 53\% kwamen de herinneringen terug toen respondenten van anderen hoorden over hun gedrag. Opmerkelijk is dat in $34 \%$ van de gevallen de herinnering helemaal niet meer terugkwam. In $11 \%$ van deze respondenten ging het om een deviante vorm van gedrag.

Als we kijken naar verschillen in drinkgedrag tussen drinkers die nooit een black-out zeggen te hebben gehad en de drinkers die dat wel beweren te hebben gehad, blijkt dat de eerste groep minder vaak vijf of meer alcoholische consumpties op een avond drinlt: $t(210)=2,94, p<0,01$. De eerste groep dronk gemiddeld drie keer per maand $(s D=2,7)$, terwijl de black-outgroep gemiddeld vijf keer per maand $(s D=4,3)$ dronk.

\section{Rijden onder invloed}

Het verband tussen alcoholgebruik en black-out werd nader onderzocht bij een groep van 101 personen die wegens rijden onder invloed waren aangehouden. In deze gevallen verzocht het $\mathrm{CBR}$ een psychiater om een advies over de rijgeschiktheid uit te brengen. Een negatief advies betekent doorgaans dat het rijbewijs voor een bepaalde tijd ingetrokken blijft. De steekproef bestond uit 93 mannen en 8 vrouwen die om verschillende redenen waren aangehouden zoals opvallend rijgedrag $(n=48)$, aanrijdingen $(n=42)$ of standaardcontrole $(n=10)$. Het gemiddelde promillage bij aanhouding was $1,9 .(S D=0,53$; range $0,66-3,5$ )

Van de 101 personen gaven er $14(14 \%)$ te kennen een 
black-out voor de aanhouding/aanrijjding te hebben. Het alcoholpromillage van de personen met amnesie bleek opvallend genoeg echter niet verhoogd te zijn ten opzichte van de andere overtreders (respectievelijk 1,8 en 1,9 promille, $t(91)<1,0$ ). De automobilisten met amnesie bleken zich wêl te onderscheiden in de wijze waarop zij waren aangehouden: van de 14 personen met een black-out waren er $12(85 \%)$ naar aanleiding van een aanrijding aangehouden. Dit percentage lag bij de aangehouden personen zonder amnesie op $35 \%\left[\chi^{2}(2)\right.$ $=12,9, p=0,002]$.

Daarnaast werd de 101 automobilisten de vraag voorgelegd of zij ooit in hun leven wel eens een black-out ten gevolge van alcoholgebruik hadden meegemaakt. Het percentage dat dit beaamde, lag opmerkelijk veel lager ( 15 van de 97 proefpersonen oftewel $15 \%)$ dan in onze algemene steekproef $(67 \%)$.

\section{Bestaan black-outs voor delicten?}

Aan het begin van dit stuk vroegen we ons af welk soort gebeurtenis ten prooi valt aan alcoholblack-outs en welke hoeveelheden alcohol daarmee dan gemoeid zijn. Daarnaast waren we geïnteresseerd of black-outs in een gewone, Nederlandse steekproef net zo regelmatig gerapporteerd worden als in Amerikaanse surveys.

Allereerst laten onze resultaten zien dat in de algemene populatie - dus buiten de rechtszaal - gerapporteerde blackouts op enige schaal voorkomen. Het gaat hierbij niet om herinneringen gefragmentariseerd of vertroebeld door intoxicatie: maar liefst $34 \%$ van onze respondenten zei dat de herinneringen nooit meer terugkwamen. Hier zou gesproken kunnen worden van een totale black-out. Ten tweede lijkt het drinkgedrag een belangrijke rol te spelen in het al dan niet krijgen van een black-out. De bloedalcoholconcentraties die af te leiden zijn uit de door de drinkers met black-outs gerapporteerde alcoholdoses, blijken extreem hoog. Hierbij moet echter als kanttekening worden geplaatst dat het om een subjectieve schatting gaat van de geconsumeerde hoeveelheid alcohol bij een gelegenheid waarvoor iemand achteraf een black-out heeft. De kans dat de gerapporteerde doses niet helemaal correct zijn, is dus aanzienlijk. Daarbij kan ook een attributiefout gemaakt worden: respondenten die geen herinnering blijken te hebben, schrijven dit ten onrechte toe aan alcoholconsumptie en overschatten vervolgens de dosis.

Daarmee komen we op het volgende punt: het soort gebeurtenis dat ten prooi valt aan een black-out en de waarschijnlijkheid dat een ernstig delict vergeten wordt. In onze eerste studie bleken de vergeten gebeurtenissen in het algemeen vrij onschuldig. Ze varieerden van 'het vergeten met wie gesproken te hebben' tot 'het vergeten hoe thuis gekomen te zijn'. In $20 \%$ en $12 \%$ van de black-outs ging het om respectievelijk wangedrag of ernstigere incidenten zoals een ruzie, vechtpartij of vernieling. Ofschoon niet duidelijk is hoe serieus het beschreven wangedrag precies was en in hoeverre men zich motorisch heeft moeten inspannen, suggereren deze cijfers dat mensen wel degelijk onder invloed van alcohol delictwaardig gedrag kunnen vergeten, zij het dat dit een fenomeen is dat niet vaak voorkomt. De respondenten die een black-out rapporteerden voor wangedrag hadden ook aanzienlijk hogere $B A C$ 's dan de mensen die minder ernstige gedragingen waren vergeten. De kanttekening dat hier een black-out als gelegenheidsargument werd gebruikt, is minder overtuigend omdat de vragenlijsten anoniem werden ingevuld. Een gênante gebeurtenis kon verzwegen worden als de respondent haar niet wilde opschrijven. Het is, zoals gezegd, wel denkbaar dat het aantal genuttigde alcoholische consumpties en dus de corresponderende BAC's werden overschat.

Bij de rijders onder invloed lijken motivationele overwegingen bij het claimen van een black-out wél een prominente rol te spelen. De BAC's van de chauffeurs met en zonder black-out verschilden niet van elkaar. Aangezien de overgrote meerderheid van de automobilisten die een black-out rapporteerden een aanrijding had veroorzaakt $(85 \%)$, lijkt de black-out te worden gebruikt als gelegenheidsargument om het gedrag te verontschuldigen. Veelzeggend is ook dat de meeste betrokkenen beweerden nooit eerder een black-out te hebben gehad. Slechts $15 \%$ gaf te kennen bekend te zijn met black-outs, wat scherp contrasteert met het percentage van $67 \%$ dat we vonden in onze algemene steekproef.

Dat overtreders minder vaak bekend zeggen te zijn met black-outs heeft natuurlijk alles te maken met het feit dat zij voor de uitkomst van het psychiatrisch onderzoek moeten vrezen indien zij volkomen open zouden zijn over hun blackouts. Onze conclusie luidt derhalve dat niet alleen bij het claimen van black-outs, maar ook bij het ontkennen daarvan strategische overwegingen een tol kunnen spelen. Om het nog eens anders te zeggen: het claimen van een black-out kan een vorm van 'fake bad' zijn die een zware verkeersovertreding beoogt te verontschuldigen. Maar evenzeer kan het ontkennen van een black-out een vorm van 'fake good' (Cima, 2003) zijn die tot doel heeft invordering van het rijbewijs op grond van ongunstig psychiatrisch advies te voorkomen.

Van geval tot geval zou men moeten nagaan of een blackoutclaim plausibel is. Idealiter moet daarbij ook worden gekeken naar de BAC. Als deze lager is dan 2,0 promille neemt de plausibiliteit van een black-out af (Kalant, 1996). In onze tweede studie lagen de BAC's in $54 \%$ van de gerapporteerde blackouts beneden de 2,0 . Delaagste waarde was 1,3 promille. In onze eerste studie rapporteerde $28 \%$ van de respondenten blackouts bij promillages lager dan 2,0 en 7\% zelfs bij promillages lager dan 1,0. Met name in die laatste categorie is het farmacologisch gezien onwaarschijnlijk dat een black-out optrad.

Om meer zekerheid te verkrijgen of er ten tijde van een delict sprake kon zijn van een alcoholblack-out, is het dus raadzaam om vrij snel na het delict door middel van een bloedproef de hoeveelheid alcohol in het bloed te meten. Bij promillages vanaf 2,0 neemt de kans dat een black-outclaim bonafide is toe. Als er geen BAC-gegevens voorhanden zijn, kan hoogstens de aard van het gedrag nog bijdragen aan de beoordeling van black-outclaims. Aangezien de fijne motorische coördinatie vrij snel verstoord raakt na een hoge alcoholdosis, is een black-out onwaarschijnlijk voor gedrag waarbij fijne motoriek vereist was (Kalant, 1996). 
Al met al kunnen we op basis van deze bevindingen drie conclusies trekken. Om te beginnen worden black-outs vaker in de algemene populatie gerapporteerd dan in de groep van zware verkeersovertreders (respectievelijk 67\% en 14\%). Ten tweede, blijkt dat in de algemene steekproef alcoholblackouts voor wangedrag relatief weinig voorkomen, terwijl alcoholblack-outs voor verkeersongevallen relatief vaak voorkomen (respectievelijk 36\% en 85\%). Onze derde en laatste conclusie luidt dan ook dat zowel het claimen als het ontkennen van alcoholblack-outs een strategisch doel kan dienen.

Mw drs. K. van Oorsouw is researchpsycholoog en als assistent in opleiding werkzaam bij de Faculteit der Psychologie van de Universiteit Maastricht, Postbus 616, 6200 MD Maastricht. E-mail: <k.vanoorsouw@psychology. unimaas.nl>.

Prof.dr. H. Merckelbach is hoogleraar psychologie aan de Faculteit der Psychologie en de Faculteit der Rechtsgeleerdheid van de Universiteit Maastricht.

Drs. D.P. Ravelli is psychiater en werkzaam als voorzitter van de Raad van Bestuur van Algemeen Psychiatrisch Ziekenhuis RobertFleury Stichting te Leidschendam. Daamaast is hij verbonden als onderzoeker aan het Julius Centrum van de Universiteit van Utrecht. Prof.dr. H. Nijman is werkzaam als senior onderzoeker in de Forensisch Psychiatrische Instelling de Kijvelanden te Poortugaal en als visiting professor verbonden aan City University in Londen. Daarnaast is hij als universitair docent verbonden aan de Faculteit der Rechtsgeleerdheid van de Universiteit Maastricht. Mw drs. I. Mekking-Pompen is psychiater in opleiding bij de Ggz in 's-Hertogenbosch.

\section{Noten}

1. Ook bij marihuanagebruik kan als bijeffect een tijdelijke amnesie of depersonalisatie optreden die erg lijkt op een alcoholische black-out. Tevens kunnen barbituraten, benzodiazepines en bepaalde anticholinerge en psychedelische drugs leiden tot of bijdragen aan een black-out, geheugenstoornissen of complete amnesie (Polster, 1993).

2. Bij forensisch-psychiatrische patiënten die onder invloed van alcohol een moord hadden gepleegd en hieraan geen herinnering hadden, werd klinisch alcoholamnesie opgewekt. In tegenstelling tot wat op basis van de state-dependency-hypothese verwacht werd, trad geen terugkeer van de herinnering aan de moord op (Wolt, 1980).

3. De volledige vragenlijst is te verkrijgen bij de eerste auteur.

4. Black-outs ontstaan gewoonlijk nadat bloedalcoholconcentraties van $250 \mathrm{mg}$ per $100 \mathrm{ml}$ (2,5 promille) berelkt zijn (Kalant, 1996).

5. De gemiddelde bloedalcoholconcentratle (BAC) werd berekend met de volgende formule: (aantal glazen alcohol * $10 \mathrm{gr} /$ gewicht * geslacht ${ }^{\mathrm{a}}$ ) - tijdsbestek consumptie - 0,15, waarbij a vrouw $=0,66$, man $=0,72$ (www.steinfurt.net/ansgarbe)

6. 14 mensen vulden het aantal geconsumeerde drankjes voór de black-out niet in.

7. Voor 19 mensen kon geen вAс worden berekend aangezien gewicht of aantal geconsumeerde drankjes niet werd ingevuld.

\section{Literatuur}

Anthenelli, R.M., Kleln, J.L., Tsuang, J.W., Smith, T.L. \& Schuckit, M.A. (1994). The prognostic importance of blackouts in young men. Journal of studies on Alcohol, 55, 290-295.

Assefi, S.L. \& Garry, M. (2003). Absolut (R) memory distortions: alcohol placebos influence the misinformation effect. Psychological Science, 14, 77-80.
Cima, M.J. (2003). Faking good, bad, and ugly. Malingering in forensic psychiatric inpatients. Landgraaf: Groeneveldt sv.

Critchlow, B. (1986). The powers of Joln Barleycorn: beliefs about the effects of alcohol on social behavior. American Psychologist, 41, 751-764.

Crombag, H.F.M. (2002). Over opzet en schuld. In P.J. van Koppen, D.J. Hessing H.L.G.J. Merckelbach \& H.F.M. Crombag (red.), Het recht van binnen (p. 737-760). Deventer: Kluwer.

Fillmore, M.T., Vogel-5prott, M. \& Gavrilescu, D. (1999). Alcohol effects on intentional behavior: dissociating controlled and automatic influences. Experimental Clinical Psychopharmacology, 7, 372-378.

Good, M.I. (1989). Substance-induced dissociative disorders and psychiatric nosology. Journal of Clinical Psychopharmacology, 9, 88-93.

Goodwin, D.W. (1995). Alcohol amnesia. Addiction, 90, 315-317.

Goodwin, D.W., Crane, J.B. A Guze, S.B. (1969). Phenomenological aspects of the alcoholic 'blackout'. British Journal of Psychiatry, 115, 1033-1038.

Jellinek, E.M. (1946). Phases in the drinking history of alcoholics: analysis of a survey conducted by the official organ of Alcoholics Anonymous. Quarterly Journal of Studies on Alcohol, 7, 88.

Kalant, H. (1996). Intoxicated automatism: legal concept vs. scientific evidence. Contemporary Drug Problems, 23, 631-648.

Kopeiman, M.D. (1987). Amnesia: organic and psychogenic. British Journal of PSychiatry, 150, 428-442.

Kopelman, M.D. (1995). The assessment of psychogenic amnesia. In A.D. Baddeley, B.A. Wilson GF.N. Watts (Eds.), Handbook of memory disorders. New York: Wiley.

Kvavilashvili, L. \& Ellis, J.A. (1999). The effects of positive and negative placebos on human memory performances. Memory, 7, 421-437.

Neal, D.E., Scott, E.M. \& Grimsbo, R.A. (1993). A case report. Alcohol-induced blackouts during sexual intercourse: legal responsibility? International Journal of Offender Therapy and Comparative Criminology, 37, 325-329.

Polster, M.R. (1993). Drug-induced amnesia. Implications for coginitive neuropsy" chological investigations of memory. Psychological Bulletin, 114, 477-493.

Swihart, C., Yuille, J. \& Porter, S. (1999). The role of state-dependent memory in 'redouts'. International Journal of Law and Psychiatry, 22, 199-212.

White, A.M., Jamieson Drake, D.W. \& Swartzwelder, H.S. (2002). Prevalence and cor" relates of alcohol-induced blackouts among college students: results of an email survey. Journal of American College Health, 51, 117-119.

White, A.M., Matthews, D.B. \& Best, P.J. (2000). Eihanol, memory, and hippocampal function: a review of recent findings. Hippocampus, 10, 88-93.

White, A.M. (2003 in press). What happened? Alcohol-induced memory impairments. From brain function to blackouts. Alcohol Research \& Health: The Journal of the National Institute on Alcohol Abuse and Alcoholism.

Wolf, A.5. (1980). Homicide and blackout in Alaskan natives. Journal of Studies on Alcohol, 41, 456-462.

\section{Suinlinere}

\section{Do alcohol blackouts for crime exist?}

\section{K. van Oorsouw, H. Merckelbach, D.P. Ravelli, H. Nijman, I. Mekking-Pompen}

Sometimes criminal suspects claim to have had an alcoholic blackout for the crime they have committed. The question arises whether alcohol blackouts are indeed a frequently occurring phenomenon or are merely used as an excuse to minimize criminal responsibility. Frequency and type of blackout were surveyed retrospectively in a healthy sample. Also, comparison of blood alcohol concentrations was made for people who did and did not claim blackout when stopped in a traffic-control study. In the survey study, blackouts were reported frequently $(67 \%)$ in contrast to the traffic-control study $(14 \%)$, where blackouts were only reported when persons were involved in an accident $(85 \%)$. These results indicate that both the denial and the claim of blackout may have a strategic background. 